\title{
Increased CCL19 expression is associated with progression in cervical cancer
}

\author{
Xiaoshu Zhang ${ }^{1}$, Yue Wang ${ }^{1}$, Yanning Cao ${ }^{1}$, Xueshan Zhang ${ }^{1}$ and Haiya Zhao ${ }^{1}$ \\ ${ }^{1}$ Department of Immunology, Binzhou Medical University, Yantai, 264003, China
}

Correspondence to: Xiaoshu Zhang, email: xiaoshuzh67@yeah.net

Keywords: cervical cancer, CCL19, EMT, invasion, proliferation

Received: December 20, 2016

Accepted: April 26, 2017

Published: May 18, 2017

Copyright: Zhang et al. This is an open-access article distributed under the terms of the Creative Commons Attribution License 3.0 (CC BY 3.0), which permits unrestricted use, distribution, and reproduction in any medium, provided the original author and source are credited.

\begin{abstract}
Cervical cancer is the third most common cancer and the fourth leading cause of malignancy related mortality in women worldwide. CCL19 is highly expressed in human cancer cells, and ligand CCL19 binding to CCR7 induces actin polymerization and pseudopodia formation. However, whether or not CCL19 is involved in EMT of human cervical cancer needs further investigation. Using quantitative PCR and western blot analyses, we found that CCL19 is overexpressed in cervical cancer cell lines and tissues. Knockdown of CCL19 via siRNA inhibited the proliferation of cervical cancer cells by increasing apoptosis. Further analyses showed that inhibitory effects of CCL19 on cell migration and invasion were partly associated with EMT process. In conclusion, these data indicate that CCL19 is abnormally expressed in cervical cancer, indicating a novel and important role for CCL19 in cervical cancer malignant transformation.
\end{abstract}

\section{INTRODUCTION}

Cervical cancer has been generally considered as one of the most common cancers in women worldwide [1]. Certain types of the human papilloma virus (HPV) infection, particularly HPV 16 and HPV 18, are the greatest risk factors for cervical cancer [2]. Despite the great advances achieved in surgical techniques, metastatic and recurrent cervical cancer remains the major causes of cancer-related deaths [3]. Molecular alterations of tumor suppressor genes and/or oncogenes have a pivotal role in the progression of cervical cancer.

Increasing evidences indicate that both chemokines and chemokine receptors play critical roles in progression of solid tumors including cervical cancer [4-5]. Moreover, previous studies show that numbers chemokines (i.e. CCL19, CXCL12) overexpressed in various tumors, which activate tumor proliferation related signaling pathway and stimulate angiogenesis on one hand, recruit immune cells infiltrating into cancerous foci and trigger tumor associated inflammation on the other [6]. The chemokines CCL19 could modulate the inflammatory responses [7]. CCR7, one of G protein-coupled chemokine receptors, lead to alteration of cell skeleton rearrangement and cell migration by binding its ligand CCL19 [8]. Considerable studies have focused on the potential role of CCL19/ CCR7 axis in several cancers
[9-11]. However, the role of CCL19 in cervical cancer has not been comprehensively studied until recently. This study highlights the emerging role of CCL19, and suggests potential target of CCL19 pathway in cervical cancer tumorigenesis.

\section{RESULTS}

Using IHC, the CCL19 expression levels were detected in a total of 62 cervical cancer and adjacent noncancerous tissues. As shown in Figure 1, CCL19 was significantly overexpressed in tumor tissues $(88.71 \%$; $55 / 62)$ than in normal counter parts $(37.10 \% ; 23 / 62$, $P<0.001)$. Besides, CCL19 expression was positively correlated with the tumor diameter $(p=0.001)$ and TNM stage grouping $(p=0.001)$. CCL19 mRNA and protein expression were significantly higher in tumor group than in noncancerous tissue group $(p<0.01$; Figure $2 \mathrm{~A}$ and 2B). CCL19 was higher expressed in cervical cancer cell lines (C33A, HeLa, CaSki, SiHa, and ME-180) than in normal human cervical epithelial cell line H8 (Figure 3A).

In order to investigate the role of CCL19 in cervical cancer cell lines, three siRNA was used to knockdown CCL19 expression in ME-180 and HeLa which have the highest of CCL19 expression (Figure 3B and 3C). Our results showed the si-CCL19\#1 is the most efficient one to down-regulate CCL19 expression. 
CCK8 assay showed that knockdown of CCL19 attenuated cell proliferation in ME-180 and HeLa cells. Colony-formation assay showed that clonogenic survival was significantly decreased after the knockdown of CCL19 $(P<$ 0.05; Figure 4C and 4D). These data are consistent with the notion that CCL19 is required for the proliferation of cervical cancer cells. Annexin VFITC analysis was used to detect the rate of apoptosis in ME-180 and HeLa cells. The results showed that CCL19 depletion could induce a significant population of early and late apoptotic of ME-180 and HeLa cells compared with controls (Figure 5A and 5B). The results of transwell assays showed that knockdown of CCAT1 significantly repressed the migration and invasive ability of ME-180 and HeLa cells ( $p<0.001$; Figure 6A-6B).

Because EMT is the remarkable presentation for cell invasion, whether silencing CCL19 expression inhibited mesenchymal features need to be identified. As showed in Figure 7, Vimentin and N-cadherin were downregulated after CCL19 knockdown while E-cadherin was overexpressed in ME-180 and HeLa cells. Therefore, inhibition of CCL19 in cervical cancer cells makes the cell phenotype be more epithelial rather than mesenchymal. Recent studies suggest that MMP2 and MMP9 modulate cell migration and lineage development. Our results showed that MMP2 and MMP9 were found to be markedly downregulated after CCL19 interference $(P<0.001)$.

\section{DISCUSSION}

Previous studies have revealed the prevalence of cervical HPV infection in cervical cancer varies greatly worldwide [12]. Despite of the recent rapid promotion in
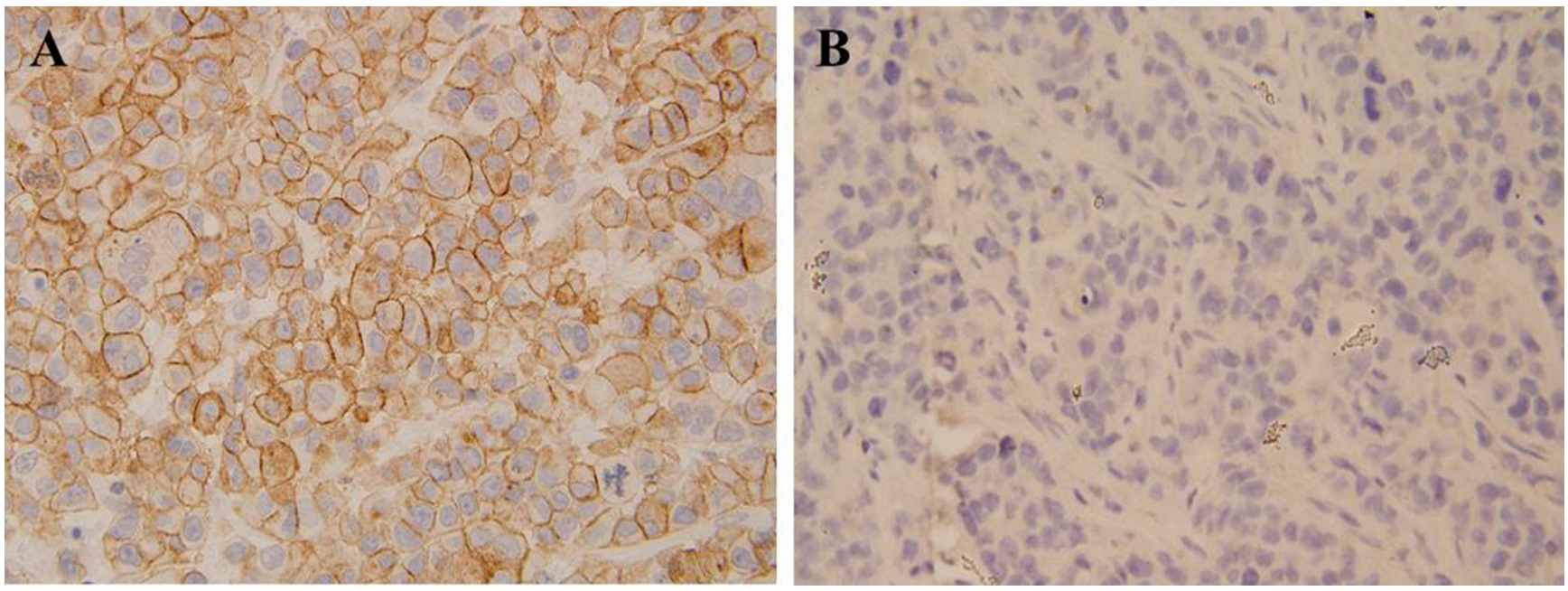

Figure 1: Immunohistochemical analysis revealed that cervical cancer tissue had stronger CCL19 expression compared with that of corresponding adjacent noncancerous tissues.

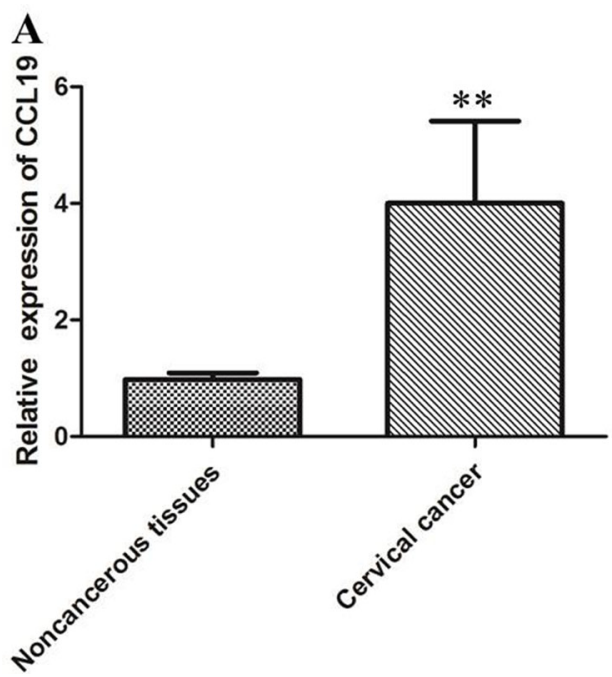

B

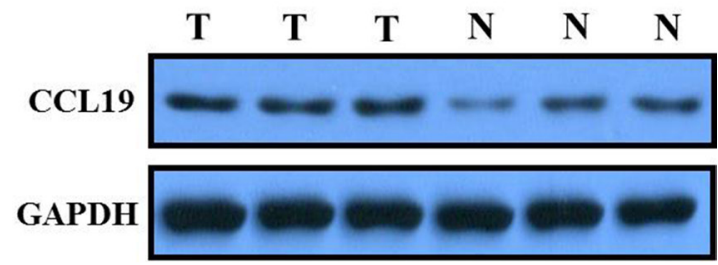

Figure 2: (A) qRT-PCR showing expression level of CCL19 mRNA in cervical cancer tissue; (B) Western blots showing the expression of CCL191 protein in cervical cancer tissue; $* P<0.05, * * P<0.01$. 

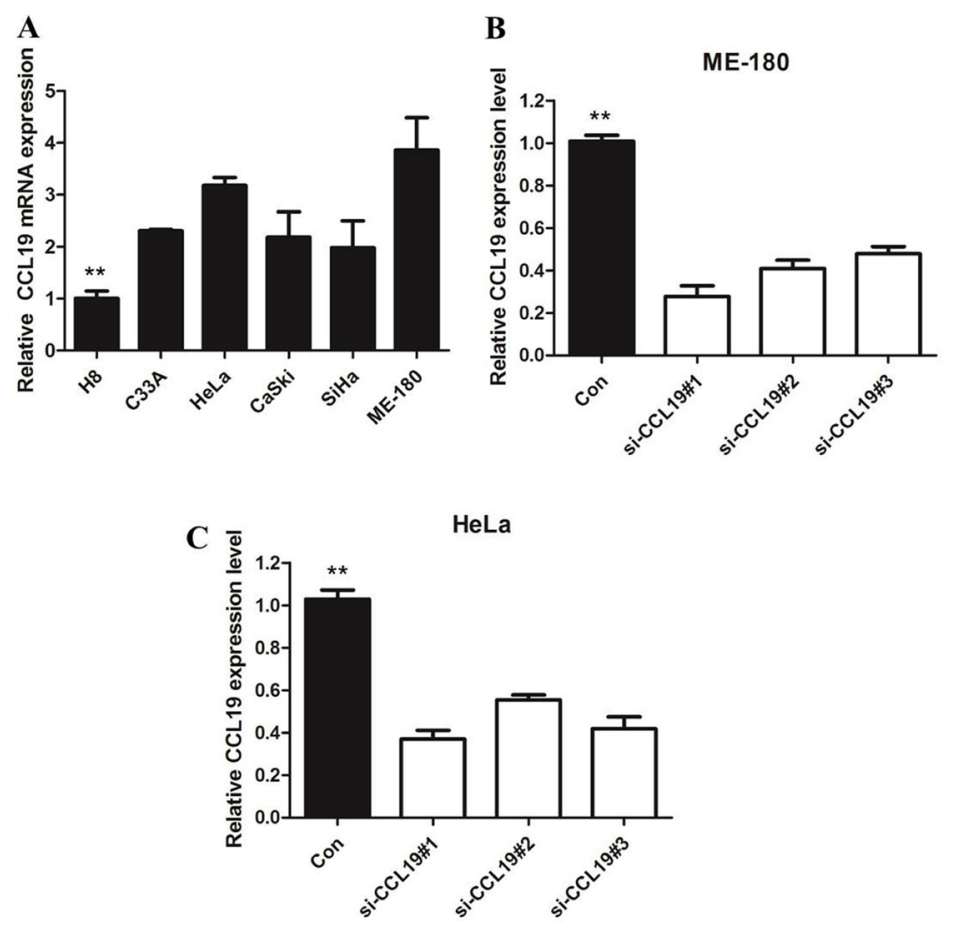

Figure 3: (A) qRT-PCR showing expression level of CCL19 mRNA in cervical cancer-derived cell lines; (B) qRT-PCR showing the expression of CCL19 mRNA in ME-180/si cells was significantly decreased compared with control cells; (C) qRT-PCR showing the expression of CCL19 mRNA in Hela/si cells was significantly decreased compared with control cells; ${ }^{*} P<0.05, * * P<0.01$.
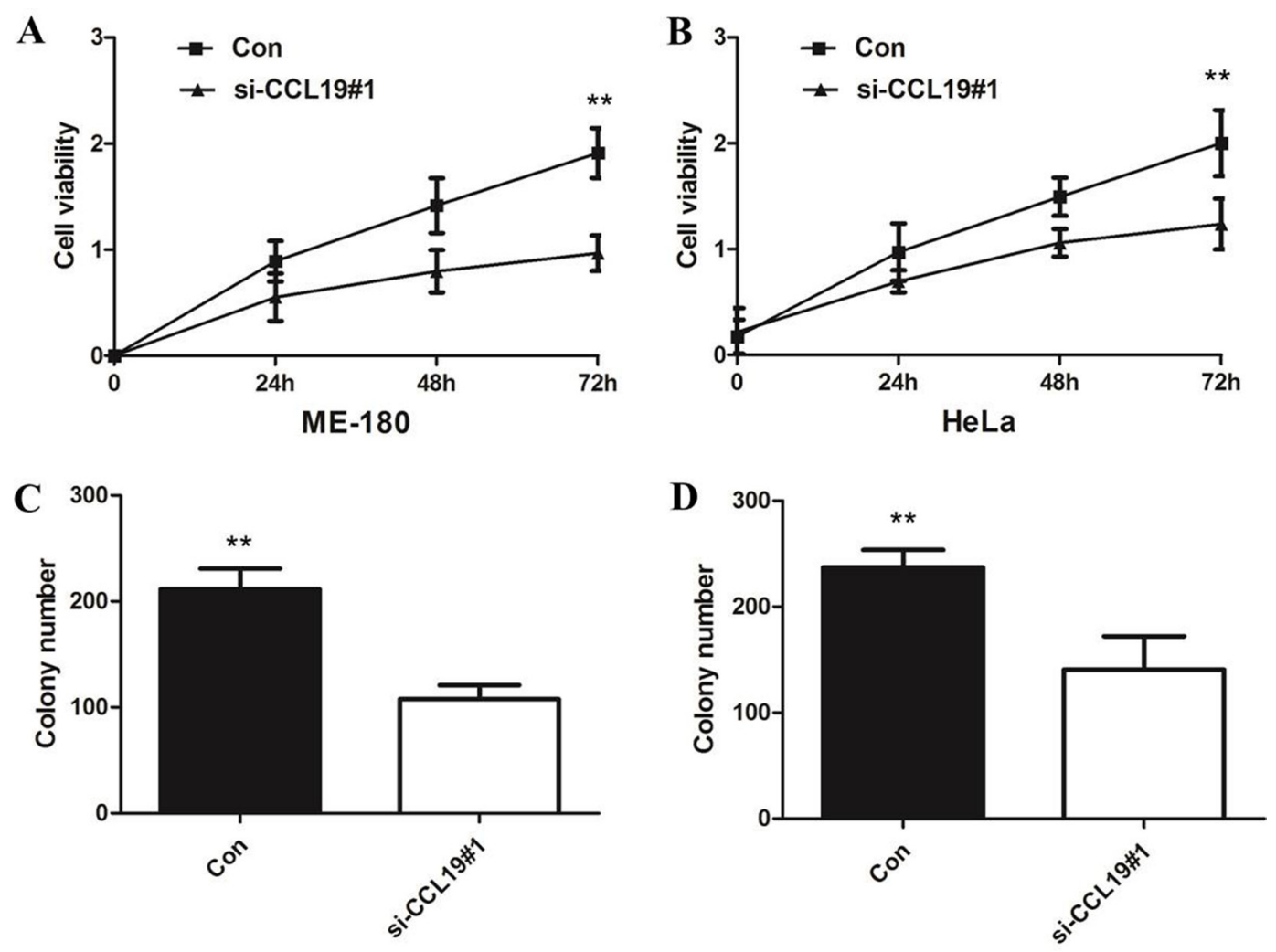

Figure 4: (A) CCK8 assay showing knockdown of CCL19 inhibited cell proliferation of ME-180 cells; (B) CCK8 assay showing knockdown of CCL19 inhibited cell proliferation of HeLa cells; (C) Colony-formation assays showed that silencing of CCL19 significantly increased the colony-forming ability of ME-180 cells; (D) Colony-formation assays showed that silencing of CCL19 significantly increased the colony-forming ability of HeLa cells; $* P<0.05, * * P<0.01$. 
the diagnosis and therapy, the prognosis of cervical cancer remains poor because the diagnosis of most of cervical cancer patients are defined at a advanced stage, and patients had lymphatic metastasis of cervical cancer [13]. Increasing evidence have demonstrated that many signaling pathways affected the development of cervical cancer, among the imbalance between oncogenes and tumor suppressor genes is responsible for the development of tumors, however the specific molecular mechanism of cervical cancer is not yet fully elucidated. Understanding its molecular mechanisms may offer the potential for the identification of new prognostic biomarkers and therapeutic targets.

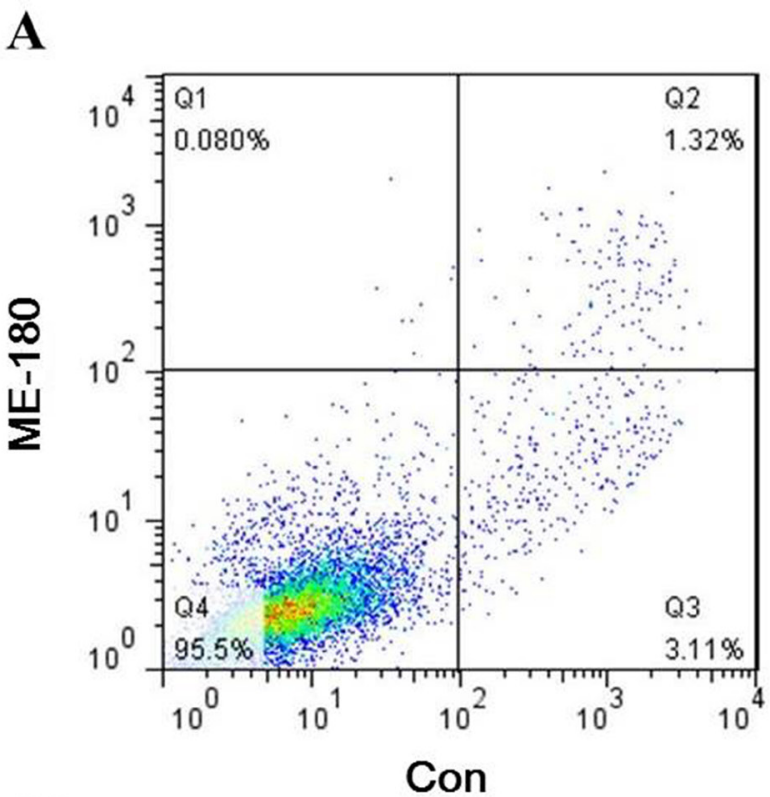

B

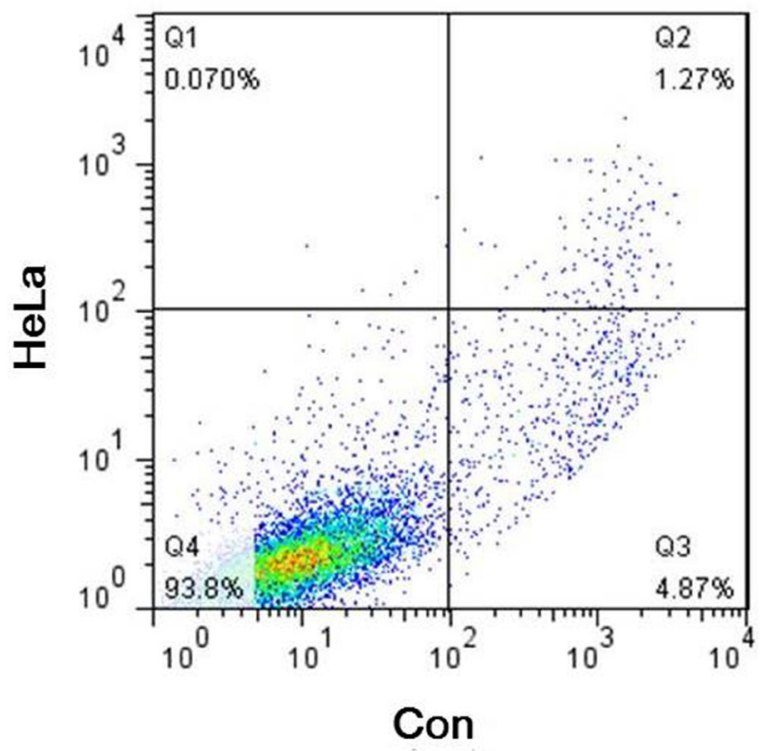

Chemokines could attract and activate cells to specific locations in the body [14-16]. Recent literatures have identified the interaction between CCL19 and human cancer cells [17]. However, whether or not CCL19 is involved in progression of human cervical cancer needs further investigation. In our study, CCL19 was firstly investigated to be upregulated in tumor tissues both at the transcription and protein level in cervical cancer. Moreover, our IHC results showed that the positive rate of CCL19 staining was $88.71 \%$ in 62 cases of cervical cancer and $37.10 \%$ in 62 cases of peritumoral tissues. Besides, we also found that all cervical cancer-derived
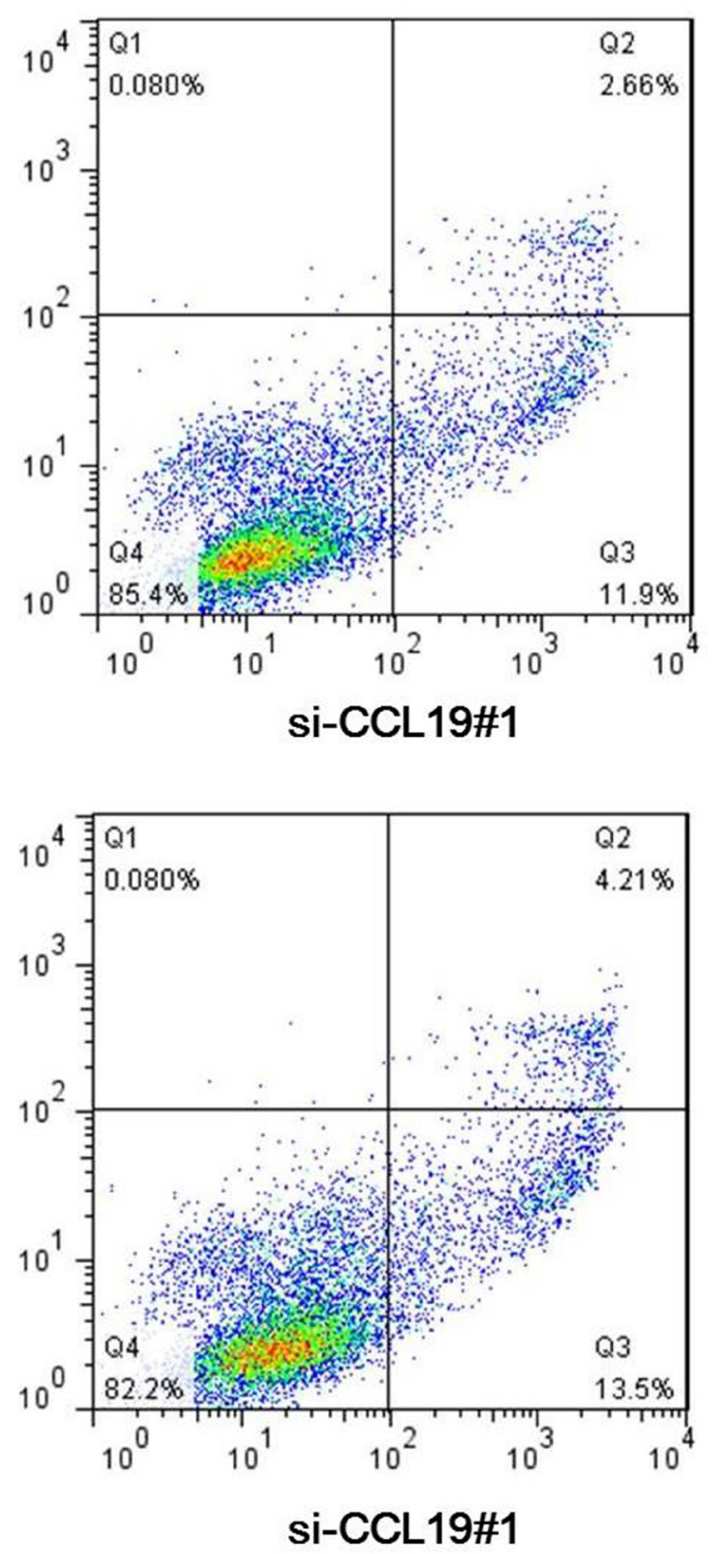

Figure 5: (A) Down-regulation of CCL19 expression by siRNA increased apoptosis in ME-180 cells; (B) Down-regulation of CCL19 expression by siRNA increased apoptosis in HeLa cells; 
cell line expressed higher CCL19 than the normal human cervical epithelial cell line H8, especially for ME-180 and HeLa cells. In fact, CCL19 has already been found to be overexpressed in various carcinomas [18-20].

To further illustrate the role and function of CCL19 in cervical cancer, we knockdowned the CCL19 expression in cervical cancer cell lines ME-180 and HeLa. Our results showed that silencing of CCL19 significantly inhibited cell proliferation, colony formation, migration and invasion of cervical cancer cells. These results demonstrated that CCL19 is associated with malignant transformation and promoted cancer growth in cervical cancer, which is consistent with previous study of CCL19 in other cancer cells [18-20]. Moreover, down-regulation of CCL19 expression induces apoptosis in ME-180 and HeLa cells, indicating that knockdown of CCL19 led to growth inhibition of cervical cancer in vitro might be correlated with cell apoptosis enhancement.

EMT is a vital process by which epithelial cells lose polarity and adhesion, and gain migratory and invasive properties, which has been associated with pathogenesis of tremendous cancers, including cervical cancer [21-22]. Moreover, the EMT phenotype was reported to be associated with tumor invasion, carcinoma metastasis, drug resistance and stem cell proportion [23-24]. Here, we confirmed that knockdown of CCL19 suppressed EMT through the downregulation of vimentin, consistent with upregulation of E-cadherin in cervical cancer cells. MMP-2 and MMP9 are members of metalloproteases family that can degrade extracellular matrix proteins. Previous studies demonstrated that the expression of MMP-2 and MMP-9 is crucial in cervical cancer metastasis [25]. High MMP2 and MMP9 expression are thought to be crucial for the migration and invasion. Our results showed that inhibition of CCL19 inhibited expression of MMP-9 and MMP-2, suggesting that CCL19 increase the aggressiveness of cervical cancer cells, possibly by regulation of MMP-2 and MMP-9.

In summary, the present study revealed that CCL19 was up-regulated in cervical cancer tissues. Besides, our study highlighted the interaction between CCL19 and
A

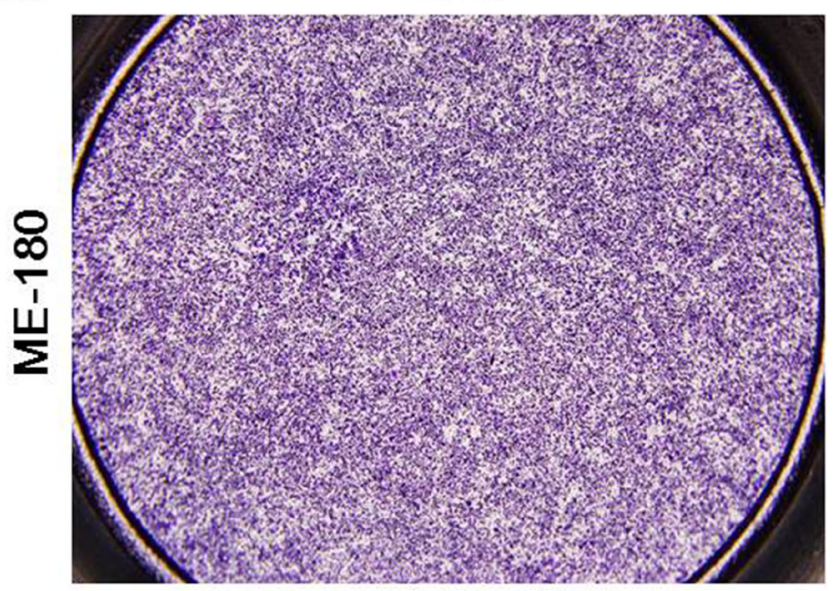

B

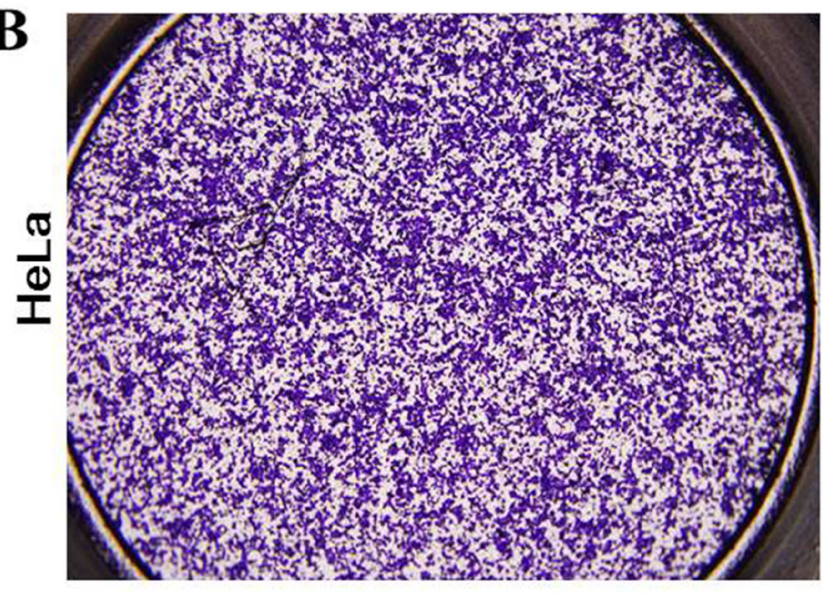

Con

\section{si-CCL19\#1}
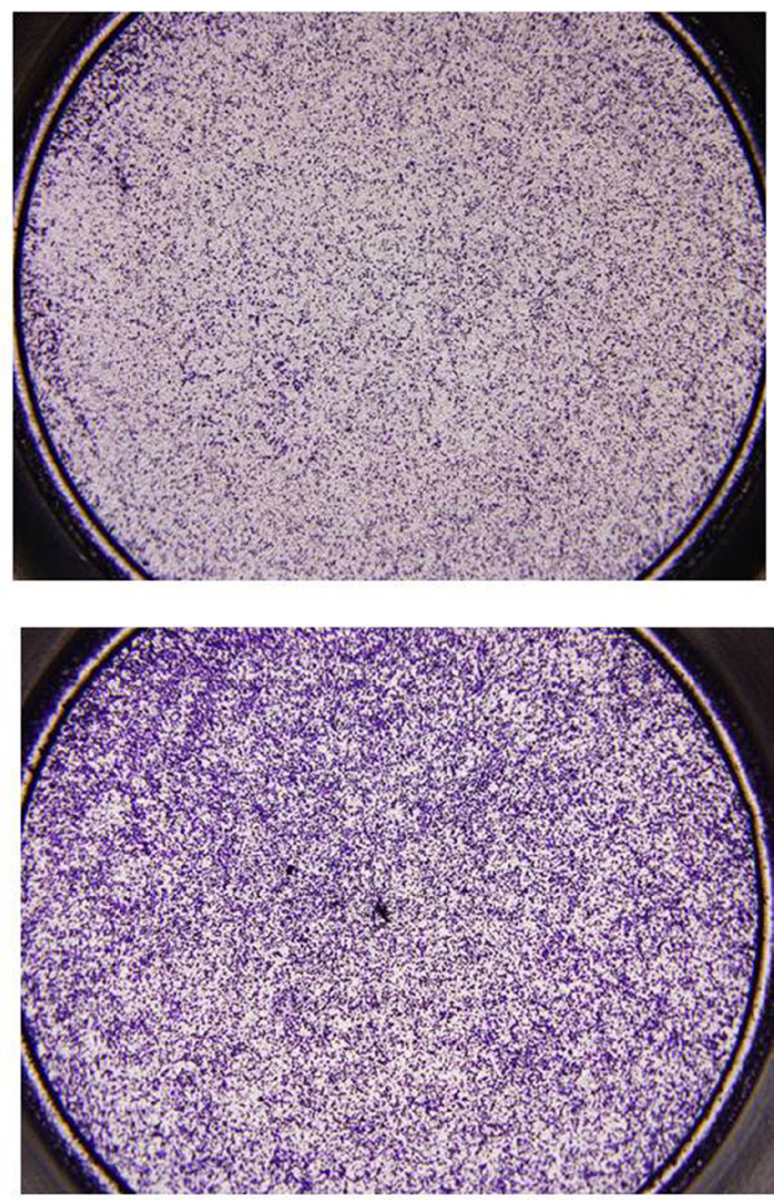

si-CCL19\#1

Figure 6: (A) Inhibition of Migration and Invasion of ME-180 cells by CCL19 siRNA; (B) Inhibition of Migration and Invasion of HeLa cells by CCL19 siRNA; 
cervical cancer cell proliferation, migration, invasion. Our findings provide new insights into the function of CCL19 in the development of cervical cancer and suggest that CCL19 might be considered as a potential target for the cervical cancer therapies in the future.

\section{MATERIALS AND METHODS}

\section{Clinical specimens}

A total of 62 cervical cancer tissues and adjacent normal tissues were collected from patients who underwent surgical resection between 2010 and 2014 . Clinical information was obtained using the database of patients. None of the patients had received previous radiotherapy, chemotherapy, or other treatments before surgery. The clinical stage was determined by using the International League of Gynecology and Obstetrics (FIGO). After surgical removal, the tissues were frozen immediately in liquid nitrogen until use. The tissues were formalin-fixed and paraffin-embedded for histopathologic diagnosis and immunohistochemical staining.

\section{Cell culture}

Five cervical cancer cell lines (C33A, HeLa, CaSki, $\mathrm{SiHa}, \mathrm{ME}-180)$ and a normal human cervical epithelial cell line (H8) were maintained at $37^{\circ} \mathrm{C}$ in an atmosphere of $5 \% \mathrm{CO}_{2}$ in DMEM with $10 \%$ fetal bovine serum.

\section{Immunohistochemistry}

Paraffin-embedded tissue blocks were cut into $2-\mu \mathrm{m}$-thick serial sections, deparaffinized in xylene and rehydrated by using descending concentrations of ethanol.
After antigen retrieval by microwave heating or pressure cooking, the slides were immersed in 3\% hydrogen peroxide to block endogenous peroxidase. Then each section was incubated successively with anti-CCL19 primary antibody (R\&D, Minneapolis, MN, USA) at $4^{\circ} \mathrm{C}$ overnight and the corresponding secondary antibody at $25^{\circ} \mathrm{C}$ for $30 \mathrm{~min}$. Subsequently, 3,3'-diaminobenzidine and hematoxylin were used for color development and counterstain, respectively. Besides, one section of each block was picked and routinely stained with hematoxylin and eosin for standard pathological diagnosis. All immunohistochemistry and hematoxylineosin slides were reviewed by two pathologists to confirm the diagnoses. PBS was used instead of primary antibody for negative control slides, and normal cervical epithelium was employed as the positive control. The staining intensity in epithelial cells was evaluated on the following scale: 0 for a negative stain, 1 for weak positivity, 2 for median positivity and 3 for strong positivity. The area containing positive cells was scored as 0 to $100 \%$. Next, the score was calculated as the intensity of positivity multiplied by the positive area. When the score was $<4$, it was negative or low expression; positive or high expression when the score was equal to or more than 4 .

\section{Quantitative real-time PCR}

Total RNA was extracted from tissues using TRIzol reagent (Invitrogen, Carlsbad, CA) according to the manufacturer's protocol. Amplification of cDNA was performed by specific primers. Quantitative real-time PCR was carried out by using SYBR Green PCR master mix (Applied Biosystems) on a system of Rotor-Gene 6000 (QIAGEN). GAPDH mRNA levels were used as internal control. Fold changes were calculated and normalized using the $-\Delta \Delta C T$ method and the mRNA level compared with
A

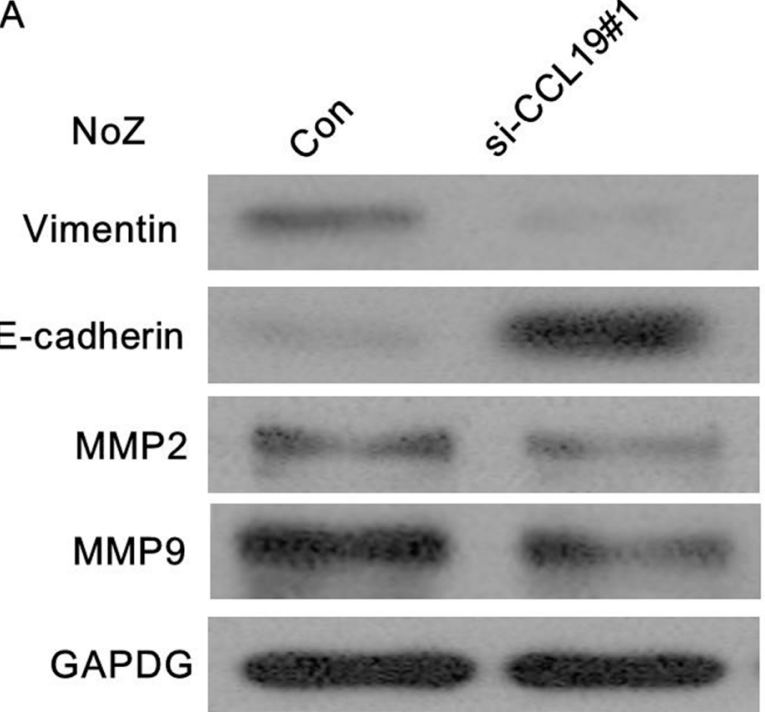

B

GBC-SD

Vimentin

E-cadherin

MMP2

MMP9

GAPDH
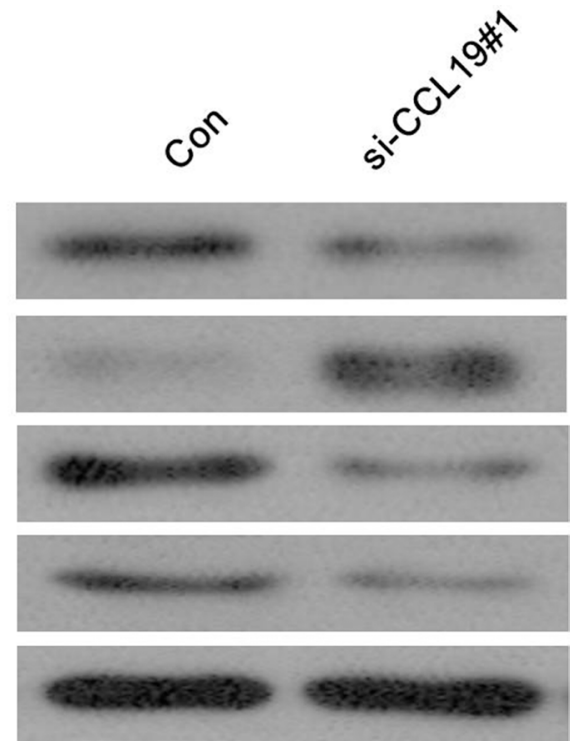

Figure 7: (A) Knockdown of CCL19 reverses EMT in ME-180 cells; (B) Knockdown of CCL19 reverses EMT in HeLa cells. 
those of controls. PCR primers were as follows: CCL19 sense primer: 5'-GTGACCTGCATTAACTCTTTACTTGC-3'; antisense primer: 5'-TATGGCTCTGGCTCTACTGGTTG-3'. Glyceraldehyde 3-phosphate dehydrogenase (GAPDH) sense primer: 5'-GGACCTGACCTGCCGTCTAG-3'; antisense primer: 5'-GTAGCCCAGGATGCCCTFGA-3'.

\section{Western blotting analysis}

Total protein from cultured cells was extracted in cell lysis buffer (PIERCE, Rockford, IL) and quantified using the Bradford method. Fifty micrograms of protein were loaded and separated on SDS-PAGE (12\%). After transferring to a polyvinylidene fluoride membrane (Millipore, Billerica, MA), the membrane was incubated overnight at $48^{\circ} \mathrm{C}$ with polyclonal goat anti-human CCL19 (N-18; sc-9777, Santa Cruz Biotechnology, Inc., Santa Cruz, CA, USA, 1:100) and mouse polyclonal antiGAPDH antibody (Santa Cruz Biotechnology; 1:1,000). After incubation with peroxidase-conjugated anti-mouse IgG (Santa Cruz Biotechnology) at $37^{\circ} \mathrm{C}$ for $2 \mathrm{~h}$, bound proteins were visualized using ECL (Pierce) and detected using BioImaging Systems (UVP Inc., Upland, CA). The relative protein levels were calculated by normalizing to $\beta$-actin protein as a loading reference.

\section{Transfection}

Cells were plated in six-well plates. Twenty-four hours later, the cells were transfected with control siRNA or with CCL19 siRNA (Santa Cruz, CA, USA) using siRNA transfection reagent (Santa Cruz Biotechnology, Inc.) according to the manufacturer's instructions.

\section{Cell proliferation assay}

Cell proliferation was measured using the cell counting kit-8 (CCK-8) (Dōjindo Laboratories, Shanghai, China). Cells were seeded at a final concentration of $4 \times 10^{4}$ cells/well and cultured in 96-well flat-bottomed microplates. Then, CCK-8 reagent $(10 \mu \mathrm{L})$ was added to each well containing $100 \mu \mathrm{L}$ of culture medium, and the plates were incubated for $2 \mathrm{~h}$ at $37^{\circ} \mathrm{C}$. Viable cells were evaluated by absorbance measurements at $450 \mathrm{~nm}$ using an auto microplate reader. $\mathrm{OD}_{450}$ was proportional to the degree of cell proliferation. All experiments were performed five times in three independent experimental trials.

\section{Colony formation assay}

Cells were plated into three 6-cm cell culture dishes after transfected with siRNA or control siRNA. Cells were incubated for two weeks in complete growth media. Cell colonies were fixed with cold methanol stained with $0.1 \%$ crystal violet for $30 \mathrm{~min}$. The colonies were manually counted using a microscope.

\section{Apoptosis analysis}

At transfection, cells were harvested and washed with ice-cold phosphate-buffered saline twice. Then, cells were re-suspended in annexin v-binding buffer and the indicated amount of propidium iodide and annexinV-FITC (BD Pharmingen, San Diego, CA, USA) was added. Cells were analyzed by flow cytometry (Calibur, BD, USA). The proportion of apoptotic cells (Annexin-V positive cells) were shown as the mean $\pm \mathrm{SD}$.

\section{Transwell migration assays}

Tumor cell in vitro migration assays was carried out using Transwell system with polyethylene terephthalate membrane (24-well inserts, $8.0 \mu \mathrm{m}$; Corning). After transfection, tumor cells were detached and re-suspended in serum free medium. Cells were added to the top champers. Complete growth medium was added to the bottom wells as migration stimulation. After incubation for 18 hours, cells on the membrane of top chambers were fixed with $90 \%$ ethanol and subsequently stained with $0.1 \%$ crystal violet. Quantification was performed by measuring OD value at a wavelength of $570 \mathrm{~nm}$.

\section{Statistical analysis}

Data analyses were performed using SPSS statistical package 15.0. Patient characteristics are shown as the mean \pm SD for continuous variables, and as the count and percent for discrete variables. Phenotypic differences in quantitative traits were assessed by genotype using the $t$ test or ANOVA. Differences in the distribution of qualitative traits by genotype were assessed by standard chi-square analysis and Fisher's exact test. A $P$ value less than 0.05 was considered significant.

\section{CONFLICTS OF INTEREST}

None.

\section{FUNDING}

Support by the National Natural Science Foundation of China (81001300) and the Foundation for Distinguished Young Scientists of Shandong Province, China (2008BS03013).

\section{REFERENCES}

1. Lea JS, Lin KY. Cervical cancer. Obstet Gynecol Clin North Am. 2012; 39:233-53. https://doi.org/10.1016/j. ogc.2012.02.008.

2. Xiong Y, Sun F, Dong P, Watari H, Yue J, Yu MF, Lan CY, Wang Y, Ma ZB. iASPP induces EMT and cisplatin 
resistance in human cervical cancer through miR-20aFBXL5/BTG3 signaling. J Exp Clin Cancer Res. 2017; 36:48. https://doi.org/10.1186/s13046-017-0520-6.

3. Li X. Emerging role of mutations in epigenetic regulators including MLL2 derived from The Cancer Genome Atlas for cervical cancer. BMC Cancer. 2017; 17:252. https://doi. org/10.1186/s12885-017-3257-x.

4. Su ML, Chang TM, Chiang $\mathrm{CH}$, Chang $\mathrm{HC}$, Hou MF, Li WS, Hung WC. Inhibition of chemokine (C-C motif) receptor 7 sialylation suppresses CCL19-stimulated proliferation, invasion and anti-anoikis. PLoS One. 2014; 9:e98823. https://doi.org/10.1371/journal.pone.0098823.

5. Zhao J, Ou B, Han D, Wang P, Zong Y, Zhu C, Liu D, Zheng M, Sun J, Feng H, Lu A. Tumor-derived CXCL5 promotes human colorectal cancer metastasis through activation of the ERK/Elk-1/Snail and AKT/GSK3beta/ beta-catenin pathways. Mol Cancer. 2017; 16:70. https:// doi.org/10.1186/s12943-017-0629-4.

6. Hwang H, Shin C, Park J, Kang E, Choi B, Han JA, Do Y, Ryu S, Cho YK. Human breast cancer-derived soluble factors facilitate CCL19-induced chemotaxis of human dendritic cells. Sci Rep. 2016; 6:30207. https://doi. org/10.1038/srep30207.

7. Huang HL, Chiang CH, Hung WC, Hou MF. Targeting of TGF-beta-activated protein kinase 1 inhibits chemokine (C-C motif) receptor 7 expression, tumor growth and metastasis in breast cancer. Oncotarget. 2015; 6:995-1007. https://doi.org/10.18632/oncotarget.2739.

8. Kim HJ, Park J, Lee SK, Kim KR, Park KK, Chung WY. Loss of RUNX3 expression promotes cancer-associated bone destruction by regulating CCL5, CCL19 and CXCL11 in non-small cell lung cancer. J Pathol. 2015; 237:520-31. https://doi.org/10.1002/path.4597.

9. Liu FY, Safdar J, Li ZN, Fang QG, Zhang X, Xu ZF, Sun CF. CCR7 regulates cell migration and invasion through JAK2/ STAT3 in metastatic squamous cell carcinoma of the head and neck. Biomed Res Int. 2014; 2014:415375. https://doi. org/10.1155/2014/415375..

10. Itakura M, Terashima Y, Shingyoji M, Yokoi S, Ohira M, Kageyama H, Matui Y, Yoshida Y, Ashinuma H, Moriya Y, Tamura H, Harigaya K, Matushima K, et al. High CC chemokine receptor 7 expression improves postoperative prognosis of lung adenocarcinoma patients. Br J Cancer. 2013; 109:1100-08. https://doi.org/10.1038/bjc.2013.440.

11. Kodama J, Seki N, Masahiro S, Kusumoto T, Nakamura K, Hongo A, Hiramatsu Y. Prognostic factors in stage IBIIB cervical adenocarcinoma patients treated with radical hysterectomy and pelvic lymphadenectomy. J Surg Oncol. 2010; 101:413-17. https://doi.org/10.1002/jso.21499.

12. Noordhuis MG, Fehrmann RS, Wisman GB, Nijhuis ER, van Zanden JJ, Moerland PD, Ver Loren van Themaat E, Volders HH, Kok M, ten Hoor KA, Hollema H, de Vries EG, de Bock GH, et al. Involvement of the TGF-beta and betacatenin pathways in pelvic lymph node metastasis in early- stage cervical cancer. Clin Cancer Res. 2011; 17:1317-30. https://doi.org/10.1158/1078-0432.CCR-10-2320.

13. O'Hayre M, Salanga CL, Handel TM, Allen SJ. Chemokines and cancer: migration, intracellular signalling and intercellular communication in the microenvironment. Biochem J. 2008; 409:635-49. https://doi.org/10.1042/ BJ20071493.

14. Nannuru KC, Singh RK. Tumor-stromal interactions in bone metastasis. Curr Osteoporos Rep. 2010; 8:105-13. https://doi.org/10.1007/s11914-010-0011-6.

15. Hillinger S, Yang SC, Zhu L, Huang M, Duckett R, Atianzar K, Batra RK, Strieter RM, Dubinett SM, Sharma S. EBVinduced molecule 1 ligand chemokine (ELC/CCL19) promotes IFN-gamma-dependent antitumor responses in a lung cancer model. J Immunol. 2003; 171:6457-65. https:// doi.org/10.4049/jimmunol.171.12.6457.

16. Tyrinova TV, Leplina OY, Tikhonova MA, Mishinov SV, Stupak VV, Ostanin AA, Chernykh ER. CCL19/CCL21dependent chemotaxis of dendritic cells in healthy individuals and patients with brain tumors. Bull Exp Biol Med. 2015; 158:785-88. https://doi.org/10.1007/s10517015-2862-4.

17. Raju R, Gadakh S, Gopal P, George B, Advani J, Soman S, Prasad TS, Girijadevi R. Differential ligand-signaling network of CCL19/CCL21-CCR7 system. Database (Oxford). 2015; 2015. https://doi.org/10.1093/database/bav106.

18. Byers MA, Calloway PA, Shannon L, Cunningham HD, Smith S, Li F, Fassold BC, Vines CM. Arrestin 3 mediates endocytosis of CCR7 following ligation of CCL19 but not CCL21. J Immunol. 2008; 181:4723-32. https://doi. org/10.4049/jimmunol.181.7.4723.

19. Zhou Y, Huang Y, Cao X, Xu J, Zhang L, Wang J, Huang L, Huang S, Yuan L, Jia W, Yu X, Luo R, Zheng M. WNT2 promotes cervical carcinoma metastasis and induction of epithelial-mesenchymal transition. PLoS One. 2016; 11:e0160414. https://doi.org/10.1371/journal. pone. 0160414 .

20. Kucia-Tran JA, Tulkki V, Smith S, Scarpini CG, Hughes K, Araujo AM, Yan KY, Botthof J, Perez-Gomez E, Quintanilla M, Cuschieri K, Caffarel MM, Coleman N. Overexpression of the oncostatin-M receptor in cervical squamous cell carcinoma is associated with epithelialmesenchymal transition and poor overall survival. Br J Cancer. 2016; 115:212-22. https://doi.org/10.1038/bjc.2016.199.

21. Singh A, Settleman J. EMT, cancer stem cells and drug resistance: an emerging axis of evil in the war on cancer. Oncogene. 2010; 29:4741-51. https://doi.org/10.1038/ onc.2010.215.

22. Korpal M, Kang Y. The emerging role of miR-200 family of microRNAs in epithelial-mesenchymal transition and cancer metastasis. RNA Biol. 2008; 5:115-19. https://doi. org/10.4161/rna.5.3.6558.

23. Libra M, Scalisi A, Vella N, Clementi S, Sorio R, Stivala F, Spandidos DA, Mazzarino C. Uterine cervical carcinoma: 
role of matrix metalloproteinases. Int J Oncol. 2009; 34:897-903. Review. https://doi.org/10.3892/ijo_00000215.

24. Dunning NL, Laversin SA, Miles AK, Rees RC. Immunotherapy of prostate cancer: should we be targeting stem cells and EMT? Cancer Immunol Immunother. 2011; 60:1181-93. https://doi.org/10.1007/s00262-011-1065-8.
25. Chen H, Wang D, Liu Y. SASH1 inhibits cervical cancer cell proliferation and invasion by suppressing the FAK pathway. Mol Med Rep. 2016; 13:3613-18. https://doi. org/10.3892/mmr.2016.4946. 